\title{
A Review of the Literature on Corruption in Healthcare Organizations
}

\author{
Vincenzo Sforza ${ }^{1}$, Riccardo Cimini ${ }^{1}$, Alessandro Mechelli ${ }^{2} \&$ Taryn Vian ${ }^{3}$ \\ ${ }^{1}$ Department of Economy, Engineering, Society and Business, University of Tuscia, Viterbo, Italy \\ ${ }^{2}$ Department of Management \& Law, University of Rome Tor Vergata, Rome, Italy \\ ${ }^{3}$ School of Nursing and Health Professions, University of San Francisco, CA, USA \\ Correspondence: Vincenzo Sforza, Department of Economy, Engineering, Society and Business, University of \\ Tuscia, Via del Paradiso, 47 - 01100 Viterbo, Italy. E-mail: sforza@unitus.it
}

Received: February 14, 2020

Accepted: March 2, 2020

Online Published: March 12, 2020

doi:10.5539/ijbm.v15n4p98

URL: https://doi.org/10.5539/ijbm.v15n4p98

\begin{abstract}
This paper provides a systematic and bibliometric review of 80 research articles on corruption in healthcare published in peer-reviewed journals between 2006 and 2017. Findings suggest that the number of studies has increased over time with a focus on low- and middle-income countries; academic researchers have published papers in a large variety of journals and have investigated different types of corruption with various methodologies. The interest is especially focused on low- and middle-income countries where corrupt behaviors are more common. The paper suggests future research directions to a dynamic research community to facilitate anticorruption actions by public authorities.
\end{abstract}

Keywords: corruption, healthcare, systematic literature review, bibliometric literature review

\section{Introduction}

Defined by Transparency International as 'misuse of entrusted power for private gain', corruption is considered by Kumar and Bhasker (2015) a pervasive problem affecting the health sector that has penetrated people's everyday lives. According to the European Commission, the health sector is one of the areas that is particularly vulnerable to corruption (European Commission, 2017, p. 9). Savedoff and Hussmann (2006) posit that uncertainty, asymmetric information and the large numbers of actors involved are three factors that might explain why the health sector is particularly prone to corruption. Lio and Lee (2016) conclude that these factors lead to substantial market failures, stimulate massive public interventions and make it difficult to manage and monitor public healthcare, thus creating opportunities for corruption.

The objective of this paper is to provide both a systematic and bibliometric literature review of studies that deal with corruption in healthcare organizations. The coexistence of these two methods to review papers allows us to consider this research a "mixed study review". According to the taxonomy of Grant and Booth (2009), these studies combine quantitative with qualitative research or outcome with process studies. In general, there is a literature review (usually systematic) as a significant component.

The main motivation of this study is the quick growth over time of the number of publications on corruption in healthcare. Indeed, it has undoubtedly been gratifying to those interested in the topic, but it becomes difficult to understand what scholars have investigated, to identify future research opportunities or, for policy makers, to design anticorruption measures. Thus, it is important to periodically synthesize the literature. A systematic review of the literature might be useful to understand the state of the art about corruption in healthcare. The bibliometric review helps identifying the most prominent papers within a very composite research community. The breadth of researchers working in this field is useful because understanding corruption, and designing anticorruption interventions adapted to context, requires attention from different disciplines. Yet this makes it complicated for practitioners and other researchers to sift through the published literature and glean insights. These motivations justify the need for a literature review on corruption in healthcare organizations, and lead to the following research questions:

1. When, where, and by whom have papers on corruption in healthcare been published?

2. Which kinds of corruption have been investigated and with what methodologies?

3. What kinds of contexts have been studied? 
4. What are the effects produced by health sector corruption on society?

5. What are the most prominent articles on corruption in healthcare?

To implement our review of the literature, we adhere to the 'Preferred Reporting Items for Systematic Reviews and Meta-Analyses'(PRISMA) from Moher et al. (2009).

Its results contribute to the literature in the extent few papers, if any, has systematized the literature on corruption in health organizations also using a bibliometric approach. This article has also implications for policy makers. Particularly, it facilitates the identification of those phenomena within the healthcare sector characterized by possible corruptive behavior. However, policy makers should be aware that the effect of corruption reverberates throughout an economy and is not confined to specific corruption-based transactions. Actually, corruption can affect the level of investments, entrepreneurial incentives, and the design of implementation of rules or regulations regarding access to resources and assets within a country (Jain, 2001, p. 72).

In the next section, our methodological approach is detailed. In the third section, the overall findings of the systematic review are summarized to answer our research questions. The fourth section is dedicated to the discussion of research findings and it contains some concluding remarks.

\section{Methods}

Systematic literature review (Cook et al., 1997; Cooper, 1998; Denyer \& Tranfield, 2008) is a method for identifying and evaluating the quality of evidence on a topic through extensive bodies of literature (Mulrow, 1994). In contrast to traditional narrative reviews, it adopts a replicable, rigorous, scientific and transparent process (Cook et al., 1997) reducing the subjectivity that sometimes can bias narrative reviews. While it does yield higher quality studies, systematic review is time-consuming and therefore probably not the most efficient for some purposes. For instance, systematic review does not focus on dissemination of research articles. In this regard, a citation analysis evaluates the most highly cited and landmark articles.

We conducted our literature review in three phases: data collection, data analysis, and synthesis.

\subsection{Phase 1: Data Collection}

In the first step, "Database Search", we used the SCOPUS and the EBSCO Host databases in order to find the articles. The preference for SCOPUS is because it is the largest abstract and citation database of peer-reviewed literature. The choice to consider also EBSCO is to enlarge the sample of research analyzed to those published in journals that are not listed in SCOPUS. We have not considered other databases such as PubMed because of the extensive overlaps with the other databases used for the paper selection.

As eligible criteria, article must have the words "corruption" AND "health*" in the title or abstract. All "grey literature" was purposely excluded (Rothstein \& Hopewell, 2009) because published studies are more likely to maintain high-quality standards. To identify the most relevant studies within the international academic community, we limited the selection to English-language peer-reviewed journals.

In the second step "Time-frame", we selected articles that had been published or went "online first" from 2006 to 2017. In the next section we will provide evidence that the choice of this time-frame keeps most of the papers selected with the first step. This is because before 2012-2013 the absolute number of papers per-year that respond to our eligibility criteria is below 5 .

In the third step "Read abstract", through a careful analysis of the abstracts, we eliminated those articles in which corruption is not the main topic, but is mentioned only incidentally, for instance, to explain research results.

In the last step "Expert opinion", we contacted an expert in the field of corruption in healthcare and asked him to check the list of eligible publications, and to indicate possible gaps. In addition, as in Smith (2004), we sent him a copy of the paper to request general comments.

\subsection{Phase 2: Data Analysis}

Once the literature was selected, following the methodology outlined in Cooper (2010), we developed a coding guide to facilitate analysis of the articles. The coding guide identified 66 variables regarding the characteristics of the authors, the journal where the publication appeared, and the article itself. As we analysed each article, we entered these variables into an Excel database. These variables have been used to implement our systematic and bibliometric review of the literature.

To analyze the country context investigated by scholar we have downloaded additional data regarding the perceived corruption index (CPI) calculated by Transparency international, frequently used in literature (e.g., Besciu, 2016; Brewer et al., 2007), and the value of the gross domestic product (GDP) per-capita (in current 
USD) calculated by the World Bank. This allowed us to have a comprehensive picture of the contexts investigated by scholars in their research. The CPI ranks 180 countries and territories by their perceived levels of public sector corruption according to experts and business people using a scale of 0 to 100 , where 0 is highly corrupt and 100 is very clean. Because not all the studies included data on the period in which corruption has been investigated, we report these metrics for 2016 and we split countries in high and low-level of perceived corruption and GDP per-capita according to the world-wide median value of these metrics.

For our bibliometric analysis, this paper used the UCINET software to draw a network of mutual references, that is, a graph that displays the most prominent articles in the scientific discourse on corruption in healthcare. To represent a network, we build an adjacency matrix whose values are equal to 1 if the paper on raw $i$ cites the paper on column $j$ and 0 otherwise. The same software has been used to represent the network whose nodes are the articles included in our sample and whose edges denote the number of citations received by other articles.

\subsection{Phase 3: Synthesis}

In the third and final phase of our review of the literature - the synthesis phase - we tried to produce a clear picture of the studies on corruption in healthcare organizations whose main findings are exposed in the next sections. In this regard, section 3 of this paper summarizes findings.

\section{Results}

\subsection{Article Selection}

Figure 1 provides a flow diagram with the number of studies screened, summarizing our strategy to select research products to be included in the sample.

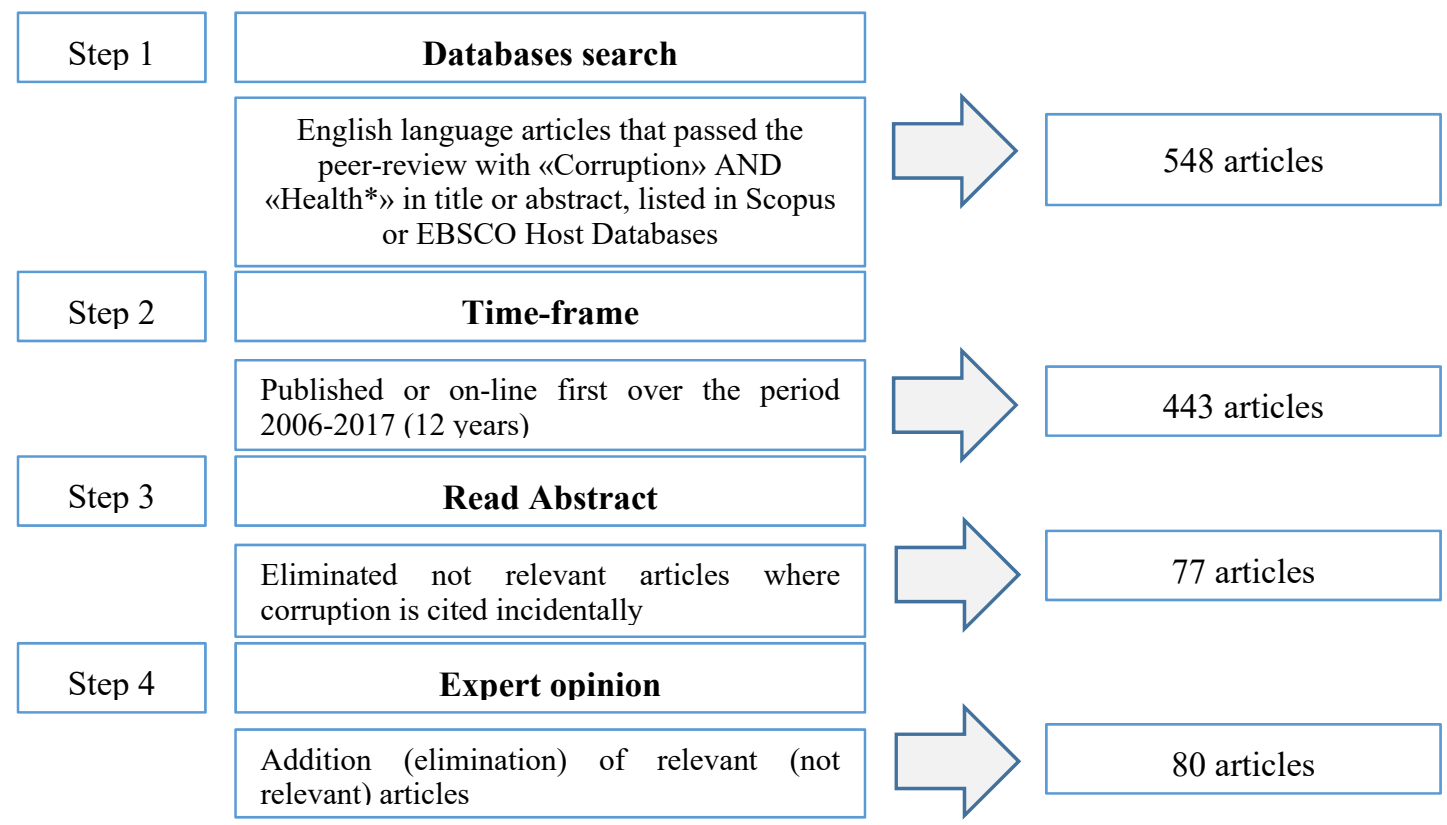

Figure 1. Article selection strategy

Note. Figure 1 shows our article selection strategy. Moving from a sample of 548 English language papers (step 1), the final number included in the sample are 80. Eliminations regard papers not published over the period 2006-2017 (step 2) as well as publications where the word "corruption" is cited incidentally (step 3) and after the inclusion/exclusion of (not) relevant articles (step 4).

The first step "Databases search", identified 548 results. Editorial and opinion pieces have been excluded from the sample. After limiting the selection to the time period (2006-2017), the number of research studies dropped to 443. In the third step "Read abstract" the number of articles drops to 77, after the elimination of products in which corruption is not the main topic, but it is mentioned incidentally, for instance, to explain research results. With the last step "Expert opinion", the number of articles rises to 80.

\subsection{Evolution Over Time, Authorships and Affiliations, Journals}

Figure 2 provides evidence that during the period analyzed, interest in the topic of corruption in healthcare has 
grown, with an increasing number of articles published in academic peer-reviewed journals especially in the last years. Indeed, the picture shows a peak of 24 articles in 2016.

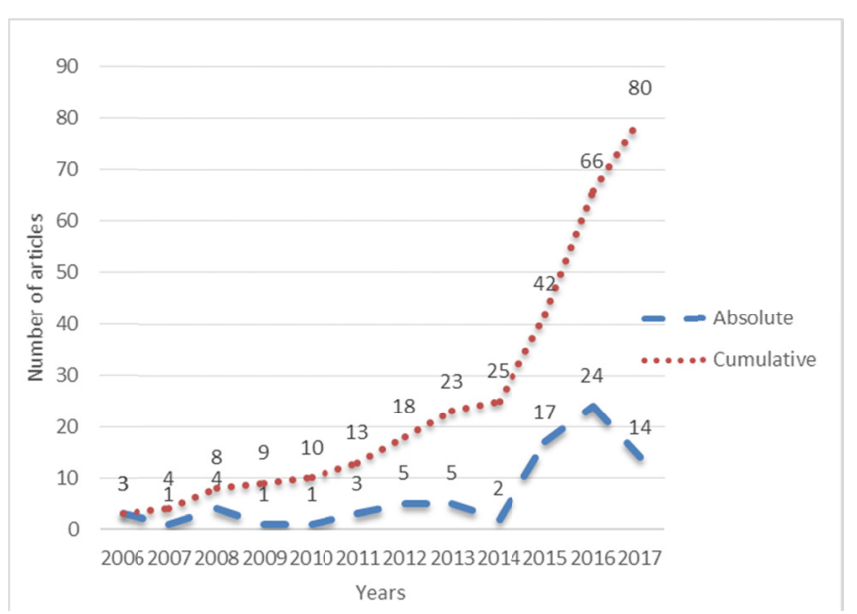

Figure 2. Evolution over time of published articles (absolute and cumulative number)

Note. Figure 2 shows the absolute and relative number of papers published during the years analyzed. The time-frame is 2006-2017.

Regarding the authors that published the papers analyzed, the 80 papers listed 206 co-authors, with 2.6 authors per publication on average. Most of the scholars interested in corruption in healthcare are affiliated with a University (i.e., academics). The peak registered in 2016 is due to papers published by academics. Scholars that are not affiliated to a University (i.e., non-academics) published irregularly during the last decade. The review of our publications suggests that $25 \%$ of articles (e.g., 20/80) included non-academics in the list of authors.

Figure 3 and Table 1 show the number of scholars per-year, distinguishing the number of authors that declare to be affiliated to a University and those that did not.

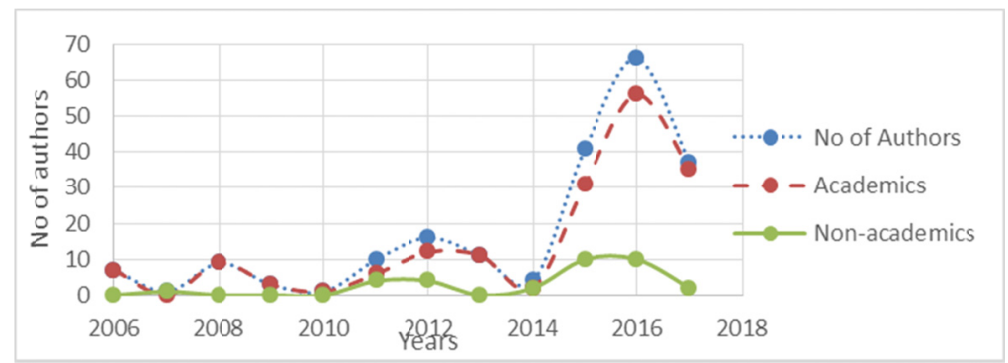

Figure 3. Evolution over time of published articles (by academics and non-arcademics)

Note. Figure 3 shows the number of authors that published papers on corruption in healthcare in the time-frame analyzed. The graph distinguishes academics by non-academics.

Table 1. Evolution over time of absolute number of published article (by academics and non-academics)

\begin{tabular}{llllllllllllll}
\hline Years & 2006 & 2007 & 2008 & 2009 & 2010 & 2011 & 2012 & 2013 & 2014 & 2015 & 2016 & 2017 & Tot. \\
\hline No of authors & 7 & 1 & 9 & 3 & 1 & 10 & 16 & 11 & 4 & 41 & 66 & 37 & 206 \\
Academics & 7 & 0 & 9 & 3 & 1 & 6 & 12 & 11 & 2 & 31 & 56 & 35 & 173 \\
Non-academics & 0 & 1 & 0 & 0 & 0 & 4 & 4 & 0 & 2 & 10 & 10 & 2 & 33 \\
\hline
\end{tabular}

Note. Table 1 reports the number of authors that published papers on corruption in healthcare in the time-frame analyzed by distinguishing academics and non-academics.

The following table completes the previous one by distinguishing for each year the nature of scholars in relation with the position their names figure in the publication. 
Table 2. Evolution over time of published articles (per position and distinguishing academics by non-academics)

\begin{tabular}{|c|c|c|c|c|c|c|c|c|c|c|c|c|c|c|c|c|}
\hline & \multicolumn{2}{|c|}{ First author } & \multicolumn{2}{|c|}{ Second author } & \multicolumn{2}{|c|}{ Third author } & \multicolumn{2}{|c|}{ Fourth author } & \multicolumn{2}{|c|}{ Fifth author } & \multicolumn{2}{|c|}{ Sixth author } & \multicolumn{2}{|c|}{ Seventh author } & \multicolumn{2}{|c|}{ Eighth author } \\
\hline 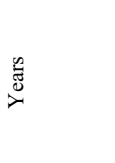 & 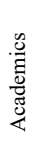 & 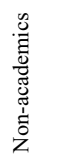 & 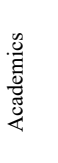 & 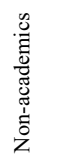 & 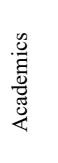 & 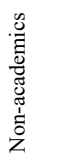 & 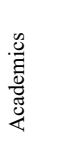 & 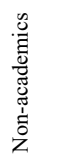 & 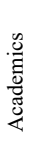 & 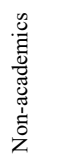 & 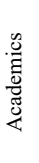 & 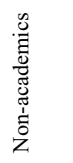 & 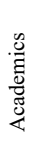 & 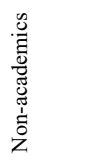 & 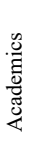 & 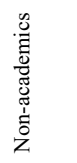 \\
\hline 2006-2009 & 8 & 1 & 5 & 0 & 3 & 0 & 2 & 0 & 1 & 0 & 0 & 0 & 0 & 0 & 0 & 0 \\
\hline $2010-2013$ & 12 & 2 & 7 & 2 & 5 & 1 & 3 & 2 & 1 & 1 & 1 & 0 & 1 & 0 & 0 & 0 \\
\hline \multirow[t]{2}{*}{ 2014-2017 } & 48 & 9 & 38 & 4 & 18 & 4 & 9 & 3 & 6 & 1 & 2 & 2 & 1 & 1 & 2 & 0 \\
\hline & 68 & 12 & 50 & 6 & 26 & 5 & 14 & 5 & 8 & 2 & 3 & 2 & 2 & 1 & 2 & $\mathbf{0}$ \\
\hline
\end{tabular}

Note. Table 2 reports the number of academics and non-academics that authored papers on corruption in healthcare, by distinguishing the position in the author list. The table distinguishes three periods that are 2006-2009, 2010-2013 and 2014-2017.

Regarding the nationality of the 206 authors' affiliations, results not tabulated show that contributors are spread across the globe. Most of them (e.g., 127/206) are in United States (32), United Kingdom (24), Brazil (14), India (13), Italy (13), Canada (11), Iran (10) and Malawi (10). The large majority (e.g., 104/127) are from high or upper-middle income countries.

Also, analyzing the names of the authors, we can find some of them figure in more than one article. For instance, while Vian authored 4 papers, researchers Gurgur, Habibov, Mackey, Matei \& O'Hare were each co-author on two studies. Collectively, these six scholars co-authored 13 articles of the 80 included in our sample (16.3\%).

As regards the source of our research products, $40 \%$ of the articles analyzed (e.g., 32/80) have been published in 10 journals listed in Scopus or in ISI Web of Science databases.

The analysis of the Aims and Scope of all these journals shows that papers on corruption in healthcare are of interest of a large spectrum of journals and published in the fields of economics, public administration, and medicine/public health.

\subsection{Type of Corruption and Methodology}

To understand "Which kinds of corruption have been investigated and with what methodologies", we provide a taxonomy of corrupt behaviors and we show the most common research protocols adopted in the papers analyzed.

As to the types of corruption, most of papers focused on corruption in general (e.g., Factor \& Kang, 2015; Buscema et al., 2017) or on multiple type of illegal behaviors (e.g., Vian et al., 2012). About $13 \%$ deals with informal payments (e.g., Stepurko et al., 2015), 4\% on fraud (e.g., Thorpe et al., 2012), 4\% on bribery (e.g., Handlos et al., 2016).

Regarding the methodological aspect, 20 articles (25\%) used qualitative methods (e.g., Brown, 2017) while 60 (75\%) used quantitative (Liaropoulos et al., 2008). Often, those that used qualitative methods investigate corruption in general; quantitative methods have been used to investigate the single type of illegal behavior by using both univariate analysis (45\%) and multivariate analysis (55\%). Univariate analysis consists in the use of descriptive statistics. Multivariate analysis may comprise methodologies such as regression models estimated by using the ordinary least squares, instrumental variables regression models, and non-linear regression models. This is quite common in health economics where an impressive diversity of applied econometric works over the past decade exist (Jones, 2000). Our analysis suggests that advanced statistical tools are becoming quite common also in the field of corruption in healthcare. In addition to the traditional descriptive statistics and linear regression models, scholars became familiar with non-linear regression models (Dood et al., 2016), principal component analysis (Buscema et al., 2017) as well as specific software able to perform system dynamic computer simulation (Somogyvári, 2013).

The variety of the methodologies adopted is the consequence of the large spectrum of corruptive behavior that a scholar might investigate in the field of corruption in healthcare. Our analysis suggests that descriptive statistics are especially used by scholars which want to investigate corruption in general. In contrast, more sophisticated statistical tools are used when a research team wants to focus on specific corruptive behavior and on the association that such behavior have with other phenomena or aspects of the human life. The variety of methodology adopted also helps explain the interest of a large spectrum of journals. Papers included in our database have been published in public administration journals (e.g., Public Administration and Development), 
medical \& public health journals (e.g., BMC Health Service Research; BMC Medicine; Journal of Cancer Policy), economics and business journals (e.g., Applied Economics Letters; Franklin Business \& Law journal; Internal Auditing and Risk Management; Management Research and Practice; Theoretical and Applied Economics), as well as journals that address ethics and the humanities (e.g., Indian Journal of Medical Ethics; Journal of Business Ethics).

\subsection{Countries Analyzed}

The third research question of this paper regards the geographic contexts authors have studied in their articles. The choice of the context investigated by scholars involved in the field of corruption in healthcare has implications for the generalizability of the research, and its relevance to regions that may have similar historical, politician or socio-cultural characteristics. The interest for certain countries has oriented the type of corruption investigated.

In our sample, $41(51.3 \%)$ articles investigated a single country, $27(33.8 \%)$ focused on two or more countries, $12(15 \%)$ are theoretical papers that did not focused on a specific country to deal with the topic of corruption in healthcare.

For research that focused on single countries, Table 3 shows that the interest is especially toward LMIC where, according to Montinola and Jackman (2002: 147), corruption is more pervasive. The table shows the list of countries investigated, the number of papers that focused on these countries, the magnitude of the perceived CPI and the values of the GDP per-capita.

Table 3. Absolute number of articles that analyzed single countries with CPI and GDP per-capita

\begin{tabular}{|c|c|c|c|c|c|c|}
\hline Countries & Type of country & No of articles & $\begin{array}{l}\text { CPI } \\
(2016)\end{array}$ & CPI Median: 38 & GDP per-capita (2016) & $\begin{array}{l}\text { GDP pc Median: } \\
5,350\end{array}$ \\
\hline Albania & Upper-middle & 1 & 39.00 & $\mathrm{HIGH}$ & $4,124.00$ & LOW \\
\hline Austria & High & 1 & 75.00 & HIGH & $44,758.00$ & HIGH \\
\hline Bosnia & Upper-middle & 1 & 39.00 & HIGH & $4,808.00$ & LOW \\
\hline Brazil & Upper-middle & 4 & 40.00 & HIGH & $8,650.00$ & HIGH \\
\hline Colombia & Upper-middle & 2 & 37.00 & LOW & $5,806.00$ & HIGH \\
\hline Congo & Lower-middle & 2 & 21.00 & LOW & $1,528.00$ & LOW \\
\hline Greece & High & 1 & 44.00 & $\mathrm{HIGH}$ & $17,891.00$ & HIGH \\
\hline Hungary & High & 1 & 48.00 & $\mathrm{HIGH}$ & $12,820.00$ & HIGH \\
\hline India & Lower-middle & 7 & 40.00 & $\mathrm{HIGH}$ & $1,710.00$ & LOW \\
\hline Iran & Upper-middle & 1 & 29.00 & LOW & $5,219.00$ & LOW \\
\hline Italy & High & 3 & 47.00 & $\mathrm{HIGH}$ & $30,661.00$ & $\mathrm{HIGH}$ \\
\hline Kenya & Lower-middle & 1 & 26.00 & LOW & $1,455.00$ & LOW \\
\hline Kuwait & High & 1 & 41.00 & HIGH & $27,359.00$ & HIGH \\
\hline Malaysia & Upper-middle & 1 & 49.00 & $\mathrm{HIGH}$ & $9,508.00$ & HIGH \\
\hline Moldova & Lower-middle & 1 & 30.00 & LOW & $1,900.00$ & LOW \\
\hline Nigeria & Lower-middle & 1 & 28.00 & LOW & $2,176.00$ & LOW \\
\hline Philippines & Lower-middle & 2 & 35.00 & LOW & $2,951.00$ & LOW \\
\hline Romania & Upper-middle & 1 & 48.00 & HIGH & $9,523.00$ & HIGH \\
\hline Senegal & Low & 1 & 45.00 & HIGH & 953.00 & LOW \\
\hline South Africa & Upper-middle & 1 & 45.00 & $\mathrm{HIGH}$ & $5,275.00$ & LOW \\
\hline Tanzania & Low & 1 & 32.00 & LOW & 878.00 & LOW \\
\hline Uganda & Low & 1 & 25.00 & LOW & 580.00 & LOW \\
\hline U.K. & High & 1 & 81.00 & $\mathrm{HIGH}$ & $40,367.00$ & HIGH \\
\hline Ukraine & Lower-middle & 1 & 29.00 & LOW & $2,186.00$ & LOW \\
\hline USA & High & 2 & 74.00 & HIGH & $57,638.00$ & HIGH \\
\hline Vietnam & Lower-middle & 1 & 33.00 & LOW & $2,171.00$ & LOW \\
\hline Total & & 41 & & & & \\
\hline
\end{tabular}

Note. The table reports the number of papers that analyzed a single country. For each of them, it provides the classification of the World Bank in high, upper-middle-, lower middle- and low-income country, the CIP index and the GDP per-capita. For these two variables, the table distinguishes countries above or below the median in relation to values of countries analyzed in the papers. 
The CPI data do not allow us to conclude that most studies focused on countries where corruption is perceived to be high. In fact, researchers included countries with different CPI results. Regarding the GDP, evidence suggests that about $56 \%(23 / 41)$ of papers that focused on single countries have studied contexts whose GDP per-capita is below the median. However, according to the classification of the World Bank, 46\% (19/41) of the papers focused on LMIC. This is due to the presence of countries with a GDP-per capita under the median that are classified in the upper-middle countries (e.g., Albania, Bosnia, Iran, South Africa).

Seven studies provided cross-continental evidence. The others focused on groups of LMIC, most of which are in Africa.

\subsection{The Effect of Corruption on Society}

The fourth research question regards the effects that corruption in healthcare has on society. Effects of corruption in society documented by research teams working in different country contexts appear similar, regardless of the type of corruption investigated or the country analyzed. The main effects include both monetary costs such as waste of health resources and non-monetary costs such as the impact on social development, health outcomes, and quality of life.

Waste is the most significant monetary cost of corruption. The problem of wasting health resources produced by corruptive behavior has been analyzed by Dias et al. (2013) in the Brazilian context. Dias et al. considered management of the funds allocated by the Federal Government to Brazilian municipalities. The findings reveal that waste affects the quality of services provided to the population. These results are like those of Bandiera et al. (2009) who focus on the Italian context and to Buscema et al. (2017), who report the estimates of the World Health Organization regarding the waste, inefficiency and corruption cost to the Italian National Health Service that are about $€ 20$ billion a year, corresponding to $20 \%$ of the total health expenditures.

Among non-monetary costs, Badawi et al. (2015) and Li et al. (2017) talk about human costs of corruption, such as child mortality. Lio and Lee (2016) claim that "more than the waste of money, corruption costs lives!". Delavallade (2006) states that because widespread corruption is detrimental to spending in education and health, corruptive behavior in healthcare organizations represent a limitation for social development. According to this scholar, this is true especially in countries with a low-level of human development, characterized by high-level of corruption, but also in the developing countries. In addition, literature suggests that social development is limited by the presence of corruption because corruptive behavior produces a lack of confidence (Radin, 2013) both in the public health system and economy that does not promote a climate of social peace (Matei, 2014). Instead of making an explicit reference to social development, some scholars refer to quality life. We can state that the deterioration of the quality life is a factor that obstruct social development. In this regard, focusing on Malaysia, Ahmad and Hasan (2016) conclude that corruption has an adverse effect on quality life by reducing the capability the country to manage public expenditure on health. In their study of informal payments in the Tanzania health sector, Mæstad and Mwisongo (2011) document the negative effect of corruption on the quality of the clinical care in terms of safety, effectiveness, patient-centeredness (courtesy), and timeliness of care.

\subsection{Who Cites Whom?}

The fifth research question regards the most prominent articles on corruption in healthcare. The network of mutual references does not include all the 80 articles that belong to our sample. This is because there are some of these articles that are not quoted by the other ones.

Figure 4 is a network that shows the mutual references of articles included in the sample.

The network shows that the community of scholars that deal with corruption in healthcare is integrated. Between the most quoted papers, there are Vian (2008), Azfar and Gurgur (2008), Gaal et al. (2006). The first one is a theoretical paper that presents a comprehensive framework and a set of methodologies for describing and measuring how opportunities, pressures and rationalizations influence corruption in the health sector. The second and the third paper are empirical research that investigate the negative effects that corruption has on the public health system of the Philippines (Azfar \& Gurgur, 2008) and the problems of informal payments in LMIC (Gaal et al., 2006). 


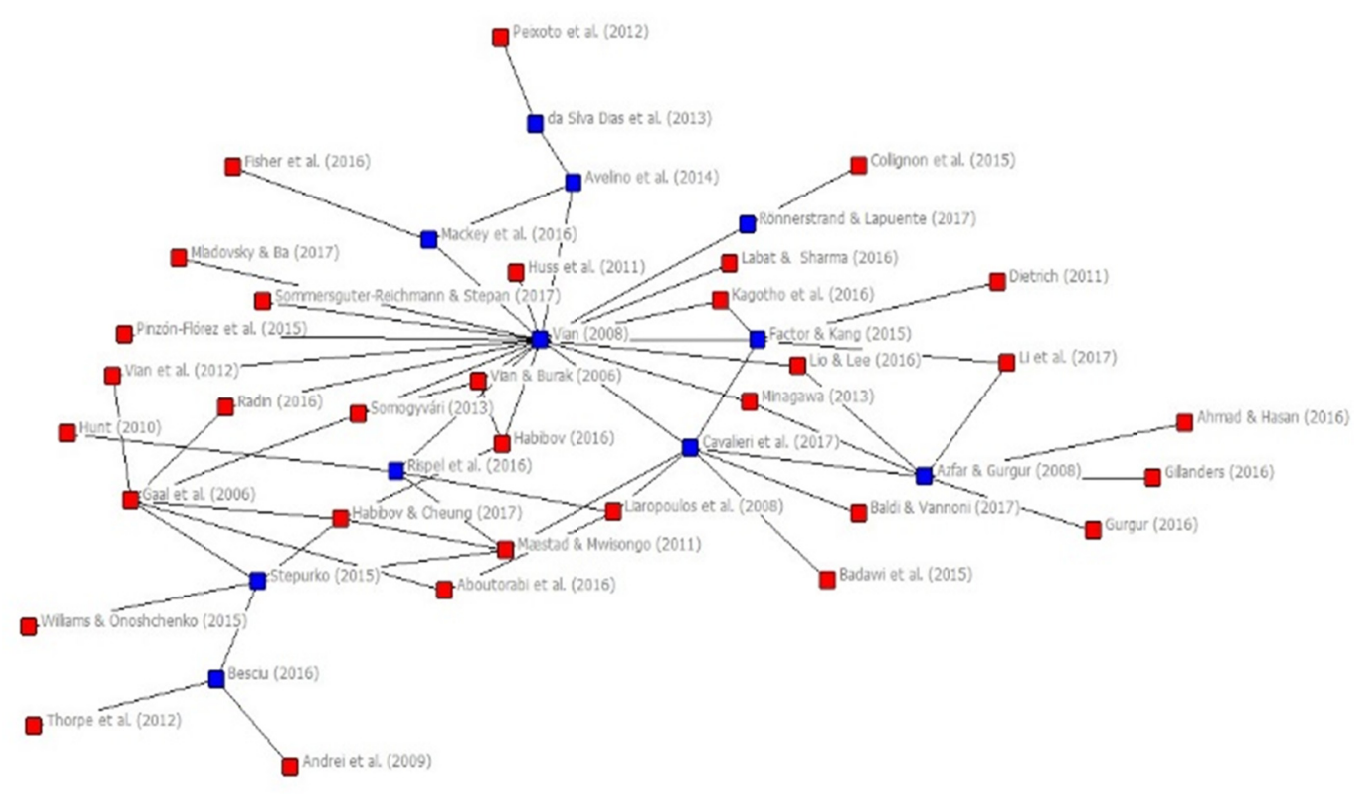

Figure 4. Network of mutual references

Note. Figure 4 shows a network useful to distinguish the most prominent articles in the community of schollars that published papers on corruption in healthcare within the time-frame analyzed.

\section{Discussion and Concluding Remarks}

Our study identifies key points about the research community studying corruption in health, methodologies being applied, and the context in which this research is being conducted. It also suggests possible future developments needed in this field of study.

The first aspect to highlight is the large variety of people that are investigating corruption in the healthcare organizations. Evidence suggests that the community is large and diversified, that is, composed by both academics and practitioners. This great interest for corruption in health might be due the fact that health sector is particularly prone to corruptive behavior, thus stimulating the interest of scholars and practitioners all over the world to investigate it. Results of the bibliometric review shows that the community is well integrated. Not only do academics and professionals collaborate in doing research, but papers written by academics are quoted very often by those of practitioners and vice-versa.

A second aspect of importance to researchers concerns the methodologies and the metrics adopted to investigate the topic. Scholars have applied quantitative and qualitative methods to produce theoretical research papers, case studies, and empirical analyses adapted for a wide spectrum of journals.

Objective measures of corruption are not so common and differ from each other for the differences of corruption concepts adopted by national legislations or at regional level.

As a result, scholars sometimes use global proxy measures such as the World Bank governance indicators (including an indicator on Control of Corruption) and the Transparency International data (e.g., Besciu, 2016; Lio \& Lee, 2016), such as Corruption Perception Index (CPI), built from surveys of experts and business people. These indicators are not specific to health sector corruption. They may be more useful at a high level to correlate health outcomes with the general level of corruption or governance, but they don't help to measure how policy changes within the health sector might impact specific types of health sector corruption (e.g., how a new whistleblowing policy might affect embezzlement of medicines by health workers).

There are also scholars that used metrics of corruption perceived by citizens (Buscema et al., 2017) obtained through interviews and surveys. Our analysis suggests that the rapidity of the diffusion of sophisticated methodologies to investigate the topic is limited by the relatively low availability of data to investigate appropriately such topics. It is often the case that scholars need to rely on proxy indicators that may not really capture the phenomena they are trying to study.

The third aspect regards the contexts investigated. Most of the research we reviewed showed a particular interest 
for LMIC, although some scholars have investigated upper-middle- or high-income countries. Probably, the interest towards LMIC is because corruption is an acute problem in poor, developing countries; however, it is not limited to this context (Rose-Ackerman, 1999). It is possible that the presence of networks that share findings about anticorruption (e.g., see the European Fraud and Healthcare Corruption Network, http://www.ehfen.org/; Sgueo, 2018) may reduce the need to investigate such topics in upper-middle- or high-income countries.

Other than influencing the interest of scholars, literature suggests that the country context might affect the effectiveness of public policies against corruption. Makuta and O'Hare (2015) confirm that the quality of governance is important in ensuring effective health care delivery and returns to investments. Assuming governance refers to the manner in which public officials and institutions acquire and exercise the authority to shape public policy and provide public goods and services. World Bank researchers consider the quality of governance as an important determinant not only of health outcomes, but also of efficiency of public spending on health (World Bank Development Committee, 2006). In their research they studied the role of good governance in modifying the effectiveness of public spending on health in improving health status in sub-Saharian Africa. Their findings validate that the impact of public health spending has the higher impact on health outcomes in countries with better governance and lower impact in countries with poor governance.

In the same vein, Ahmad and Hasan (2016) hypothesized that in poorly governed countries an increase of public spending on health is unlikely to lead to better outcomes. Their empirical analysis show that this holds true in the presence of high levels of corruption. Inefficiency in public expenditure and governance is a further motivation that could justify their hypothesis. The difficulties to collect data have not allowed scholars to demonstrate this further assumption with statistical tests. On the other hand, Besciu (2016), whose work focused on developed countries, argues that to obstruct the negative effect that corruption has on performance of the health system, a joint effort from governments is needed. Considering the European context, she recommends creating a methodology that will be unanimously accepted. These are the conclusions of her article whose results show a relationship between the CPI and the effective employment of the population, life expectancy at birth, out-of-pocket payments, and public health expenditures. Findings show that when the level of corruption increases, the results for life expectancy at birth are low, because of the quality of medical services that is seriously affected. In addition, she provides evidence that the high level of out-of-pocket payments encouraged the expansion of corruption in the medical system. A low level of effective employment of the population and a low level of public health expenditures, determine the worsening of health care capacity and generates corrupt practices for obtaining access to the healthcare system.

In this regard, literature provides evidence that the anticorruption policies are not effective. Particular attention must be dedicated to the agency theory (Ross, 1973), which is not only the predominant theory of many papers in corruption research (Ugur \& Dasgupta, 2011), but also the paradigm of many anticorruption policies (Perrson et al., 2013). The principal-agent framework examined the behavior of individuals identifying corruption as a sub-optimal outcome resulting from the interaction between an agent and a principal. According to Perrson et al. (2013), at a time when corruption is a systemic phenomenon, involving both principals and agents, the agency theory might not completely explain corrupt behavior in as much as its focus is on the individual and not the collective. The anticorruption policies build on a conceptualization of corruption as a principal-agent problem frequently use instruments based on strengthening transparency and external controls, as well as disincentivizing agents from pursuing interests which do not conform to those of the principal. These policies can effectively obstruct some types of corruption but lose effectiveness when corruption is systemic and also involves the principals (Miller et al., 2001; Karklins, 2005).

To understand the reasons for the success (or failure) of the anticorruption reforms, some scholars consider the use of the "collective action theory" useful (Ostrom, 1998; Bauhr \& Nasiritousi, 2011; Perrson et al., 2013; Baurh, 2017). Since Mancur Olson's (1965) book, this approach studies group dynamics and how they affect individuals when making decisions. In this perspective, scholars have highlighted the role on human behavior of several variables (i.e., Ostrom, 2010) such as trust, reputation, reciprocity and the combinations of both formal and informal mechanism of control.

Some different lessons should be considered from the history of improper applying principal-agent framework to inappropriate sceneries. Scholars could evaluate a widening of the boundaries of the agency theory, recognizing that in the definition of anticorruption policies the traditional scheme cannot fit all corruptive behavior. For instance, in low- and middle-income countries, monitoring costs might be absent and substituted by other agency costs, represented by (informal) payments that might lead them to have access to treatment (Pourtaleb et al., 2020). Some points for reflection should be developed from the deepening of the institutional characteristics of single countries, on which depend the possibilities that the anticorruption reforms are effectively applied. Under 
the umbrella of institutional approach, several studies highlighted that reforms are often implemented symbolically for legitimacy purposes, by conforming to external expectations of stakeholders (for all, see Cavalluzzo \& Ittner, 2004).

All these aspects reflect that the problem is a complex one, affected by country features difficult to control by regulators, and that the insights of professionals and academics from multiple disciplines can shed light on such a challenging problem.

Finally, it is worth discussing the costs of corruption for society and in particular the non-monetary ones. Public authorities could have a central role in combatting corruption in healthcare and in reducing its costs. Therefore, actions against corruption are crucial, given that reducing corruption will also minimize the adverse effects of corruption on government debt through government expenditure (Cooray et al., 2017). To combat informal payments, Aboutorabi et al. (2016) recommend educating patients and increasing income levels of employees; Habibov (2016) asks for an increase in transparency. Also, the adoption of international standards for public ethical conduct (Cooper \& Yoder, 2002) might be useful to combat corruption at an international level instead of through individual efforts. Ahmed and Azim (2015) consider education in medical ethics as the major intervention for dealing with corruption in healthcare. Although this paper examined national jurisdictions, it had difficulty in evaluating the effectiveness of such policies, which depend on country factors that are not always under the control of public authorities and regulators.

Having shed some light on current research trends, this literature review identifies possible future research opportunities. For example, scholars could develop larger databases (Dias et al., 2013) as well as indicators for specific types of corruption at the local level (Buscema et al., 2017), in particular informal payments (Gaal et al., 2006). Because a relationship is assumed between corruption and the quality of legal setting (Immordino \& Pagano, 2010) and a relationship between corruption and the institutional quality exists (Dreher et al., 2009), future research can focus more on high-income countries in order to study the effectiveness of public interventions distinguishing them according to the quality of their legal setting. "Because context matters, the subnational comparative method is necessary to capture variation" (Fox, 2015). This statement suggests the usefulness of comparative studies that investigate corruption and the impact of actions to combat illegal behavior.

The availability of data could be facilitated by improved transparency of data. In the common law countries, the Freedom of Information Act (FOIA) could provide new research opportunities. The aim of FOIA is allowing citizens to have free access to public information (available also for academics), without the traditional restrictions. Cultural constraints and different legal traditions have led civil law countries to imitate reforms introduced in the Anglo-Saxon countries. For instance, in Italy, the Legislative Decree number 97 of 2016 marked the passage from restricted to generalized access (Lunardelli, 2017). Transparency should not regard only data but also measures that inhibit corruption within the single organizations. For instance, the Decree 190 of 2012 introduced in the Italian legislation the so-called whistleblowing, that is, the possibility for worker to report certain types of wrongdoing.

Our study has several potential limitations. Despite the use of specific inclusion criteria, possible biases in the selection of publications and inaccuracy in data extraction may remain due to recognized limitations of PRISMA procedure (Moher et al., 2007). In addition, literature is subject to publication bias that could have affected our findings. Limitations typical of systematic literature review require caution in the interpretation of most results (Avenell et al., 2004). This has been in part alleviated by asking to an expert opinion to indicate possible gaps. Future studies can enlarge the sample of research products to books, editorial and other documents in order to increase the robustness of findings and to verify whether results of this paper cohere with those achieved by using larger samples. Future studies might also enhance the implementation of the models supported by theories of corruption in the health sector. Most of the papers analyzed consider corruption in the limited framework of the classical agency theory despite the presence of alternative theories that might inspire policy makers and regulators in the formulation of sound and effective anticorruption measures.

\section{Funding}

This research received no specific grant from any funding agency in the public, commercial, or not-for-profit sectors. 


\section{References}

Aboutorabi, A., Ghiasipour, M., Rezapour, A., Pourreza, A., Sarabi Asiabar, A., \& Tanoomand, A. (2016). Factors affecting the informal payments in public and teaching hospitals. Medical Journal of the Islamic Republic of Iran, 30(1), 26-35.

Ahmad, R., \& Hasan, J. (2016). Public health expenditure, governance and health outcomes in Malaysia. Journal Ekonomi Malaysia, 50(1), 29-40. https://doi.org/10.17576/JEM-2016-5001-03

Ahmed, A., \& Azim, A. (2015). Control of corruption in healthcare. Indian journal of medical ethics, 12(4), 230-232. https://doi.org/10.20529/IJME.2015.060

Avenell, A., Broom, J., Brown, T. J., Poobalan, A., Aucott, L., Stearns, S. C., Smith, W. C. S., Jung, R. T., Campbell, M. K., \& Grant, A. M. (2004). Systematic review of the long-term effects and economic consequences of treatments for obesity and implications for health improvement. NIHR Journals Library. Retrieved from https://www.ncbi.nlm.nih.gov/books/NBK62231/

Azfar, O., \& Gurgur, T. (2008). Does corruption affect health outcomes in the Philippines? Does corruption affect health outcomes in the Philippines? Economics and Governance, 9(3), 197-244. https://doi.org/10.1007/s10101-006-0031-y

Badawi, D. A., Alkhamis, Y., Qaddoumi, M., \& Behbehani, K. (2015). National transparency assessment of Kuwait's pharmaceutical sector. Health Policy, 119(9), https://doi.org/10.1016/j.healthpol.2015.07.001

Bandiera O, Prat, A., \& Valletti, T. (2009). Active and passive waste in government spending: evidence from a policy experiment. American Economic Review, 99(4), 1278-1308. https://doi.org/10.1257/aer.99.4.1278

Bauhr, M., \& Nasiritousi, N. (2011). Why pay bribes? Collective action and anti-corruption efforts. Gothenburg: The QoG Institute.

Bauhr, M. (2017). Need or greed? Conditions for collective action against corruption. Governance, 30(4), 561-581. https://doi.org/10.1111/gove.12232

Besciu, C. D. (2016). The impact of corruption in the performance management of European health system. Management Research \& Practice, 8(2), 5-22.

Brewer, G. A., Choi, Y., \& Walker, R. M. (2007). Accountability, corruption and government effectiveness in Asia: an exploration of World Bank governance indicators. International Public Management Review, 8(2), 204-225

Brown, R. C. H. (2017). Social values and the corruption argument against financial incentives for healthy behaviour. Journal of Medical Ethics, 43(3), 140-144. http://dx.doi.org/10.1136/medethics-2016-103372

Buscema, P. M., Gitto, L., Russo, S., Marcellusi, A., Fiori, F., Maurelli, G., Massini, G., \& Mennini, F. S. (2017). The perception of corruption in health: AutoCM methods for an international comparison. Quality and Quantity, 51(1), 459-477. https://doi.org/10.1007/s11135-016-0315-4

Cavalluzzo, K. S., \& Ittner, C. D. (2004). Implementing performance measurement innovations: evidence from government. Accounting, Organizations and Society, 29(3-4), 267. https://doi.org/10.1016/S0361-3682(03)00013-8

Cook, D. J., Mulrow, C. D., \& Haynes, R. B. (1997). Systematic reviews: Synthesis of best evidence for clinical decision. Annals of Internal Medicine, 126(5), 376-380.

Cooper, H. (1998). Synthesizing research (3rd ed.). Thousand Oaks, CA: Sage Publications.

Cooper, H. (2010). Research Synthesis and Meta-Analysis (4th ed.). Thousand Oaks, CA: Sage Publications.

Cooper, T. L., \& Yoder, D. E. (2002). Public management ethics standards in a transnational world. Public Integrity, 4(4), 333-352. https://doi.org/10.1080/15580989.2002.11770926

Cooray, A., Dzhumashev, R., \& Schneider, F. (2017). How does corruption affect public debt? An empirical analysis. World development, 90, 115-127. https://doi.org/10.1016/j.worlddev.2016.08.020

Delavallade, C. (2006). Corruption and distribution of public spending in developing countries. Journal of Economics and Finance, 30(2), 222-239. https://doi.org/10.1007/BF02761488

Denyer, D. \& Tranfield, D. (2008). Producing a systematic review, in Buchanan, D. (ed.), The sage handbook of organizational research methods (pp. 671-689). London: Sage. 
Dias, L. N., Matias-Pereira, J., Santana Farias, M. R., \& Souza Pamplona, V. M. (2013). Factors associated with the Waste of Health Resources Allocated by the Federal Government to the Municipalities Audited by the Office of the Comptroller General. Revista Contabilidade \& Finanças, 24(63), 206-218.

Dreher, A., Kotsogiannis, C., \& McCorriston, S. (2009). How do institutions affect corruption and the shadow economy? International Tax and Public Finance, 16(6), 773-796. https://doi.org/10.1007/s10797-008-9089-5

European Commission. (2017). Updated Study on Corruption in the Healthcare Sector (Final report).

Factor, R., \& Kang, M. (2015). Corruption and population health outcomes: an analysis of data from 133 countries using structural equation modeling. International Journal of Public Health, 60(6), 633-641. https://doi.org/10.1007/s00038-015-0687-6

Fox, J. A. (2015). Social accountability: what does the evidence really say?. World Development, 72, $346-361$. https://doi.org/10.1016/j.worlddev.2015.03.011

Gaal, P., Belli, P. C., McKee, M., \& Szócska, M. (2006). Informal Payments for Health Care: Definitions, Distinctions, and Dilemmas. Journal of Health Politics, Policy \& Law, 31(2), 251-293. https://doi.org/10.1215/03616878-31-2-251

Grant, M. J., \& Booth, A. (2009). A typology of reviews: an analysis of 14 review types and associated methodologies. Health Information \& Libraries Journal, 26(2), 91-108. https://doi.org/10.1111/j.1471-1842.2009.00848.x

Habibov, N. (2016). Effect of corruption on healthcare satisfaction in post-soviet nations: A cross-country instrumental variable analysis of twelve countries. Social Science and Medicine, 152, 119-124. https://doi.org/10.1016/j.socscimed.2016.01.044

Handlos, L.N., Olwig, K.F., Bygbjerg, I.C., \& Norredam, M. (2016). Return migrants' experience of access to care in corrupt healthcare systems: The Bosnian example. International Journal of Environmental Research and Public Health, 13(9), 924-936. https://doi.org/10.3390/ijerph13090924

Immordino, G., \& Pagano, M. (2010). Legal standards, enforcement, and corruption. Journal of the European Economic Association, 8(5), 1104-1132. https://doi.org/10.1111/j.1542-4774.2010.tb00549.x

Jain, A. (2001). Corruption: a review. Journal of Economic Surveys, 15(1), 71-121. https://doi.org/10.1111/1467-6419.00133

Jones, A. M. (2000). Health econometrics. Handbook of health economics, 1, 265-344.

Karklins, R. (2005). The System Made Me Do It: Corruption in Post-Communist Societies. Armonk, NY: M.E. Sharpe.

Kumar, R.V., \& Bhasker, S. (2015). Administrative corruption in oncology units of developing countries: Overview, its impact and possible methods to curb it. Journal of Cancer Policy, 5, 1-7. https://doi.org/10.1016/j.jcpo.2015.05.005

Li, Q., An, L., Xu, J., \& Baliamoune-Lutz, M. (2017). Corruption costs lives: evidence from a cross-country study. European Journal of Health Economics, 1-13. https://doi.org/10.1007/s10198-017-0872-z

Liaropoulos, L. Siskou, O. Kaitelidou, D. Theodorou, M., \& Katostaras, T. (2008). Informal payments in public hospitals in Greece. Health Policy, 87(1), 72-81. https://doi.org/10.1016/j.healthpol.2007.12.005

Lio, M. C., \& Lee, M. H. (2016). Corruption costs lives: a cross-country study using an IV approach. International Journal of Health Planning and Management, 31(2), 175-190. https://doi.org/10.1002/hpm.2305

Lunardelli, M. (2017). The Reform of Legislative Decree No. 33/2013 in Italy: A Double Track for Transparency. Italian Journal of Public Law, 1, 143-188.

Mæstad, O., \& Mwisongo, A. (2011). Informal payments and the quality of health care: Mechanisms revealed by Tanzanian health workers. Health Policy, 99(2), 107-115. https://doi.org/10.1016/j.healthpol.2010.07.011

Makuta, I., \& O'Hare, B. (2015). Quality of governance, public spending on health and health status in Sub Saharan Africa: A panel data regression analysis. BMC Public Health, 15(1). https://doi.org/10.1186/s12889-015-2287-z

Matei, A. D. (2014). When health is affected by corruption. Internal Auditing \& Risk Management, 9(2), 165-177. Available at SSRN: https://ssrn.com/abstract=2461467 
Miller, W. L., Grødeland, A. B., \& Koshechkina, T. Y. (2001). A Culture of Corruption? Coping with Government in Post-Communist Europe. Budapest, Hungary: Central European University Press.

Moher, D., Tetzlaff, J., Tricco, A. C., Sampson, M., \& Altman, D. G. (2007). Epidemiology and reporting characteristics of systematic reviews. PLoS Med, 4(3), 447-455. https://doi.org/10.1371/journal.pmed.0040078

Moher, D., Liberati, A., Tetzlaff, J., \& Altman, D. G. (2009). Preferred Reporting Items for Systematic Reviews and Meta-Analyses: The PRISMA Statement. PLoS Medicine, 6(7). https://doi.org/10.1371/journal.pmed.1000097

Montinola, G. R., \& Jackman, R. W. (2002). Sources of corruption: A cross-country study. British Journal of Political Science, 32(1), 147-170. https://doi.org/10.1017/S0007123402000066

Mulrow, C. D. (1994). Systematic reviews: rationale for systematic reviews. BMJ. British medical journal, 309(6954), 597-599. https://doi.org/10.1136/bmj.309.6954.597

Olson, M. (1965). The Logic of Collective Action: Public Goods and the Theory of Groups. Harvard University Press.

Ostrom, E. (1990). Governing the Commons: The Evolution of Institutions for Collective Action. New York: Cambridge University Press.

Ostrom, E. (2010). Analyzing collective action. Agricultural economics, 41, 155-166. https://doi.org/10.1111/j.1574-0862.2010.00497.x

Persson, A., Rothstein, B., \& Teorell, J. (2013), Why Anticorruption Reform Fail - Systemic Corruption as a Collective Action Problem, Governance, 26(3), 449-471. https://doi.org/10.1111/j.1468-0491.2012.01604.x

Pourtaleb, A., Jafari, M., Seyedin, H., \& Behbahani, A. A. (2020). New insight into the informal patients' payments on the evidence of literature: a systematic review study. BMC Health Services Research, $20(1), 14$. https://doi.org/10.1186/s12913-019-4647-3

Radin, D. (2013). Does corruption undermine trust in health care? Results from public opinion polls in Croatia. Social Science \& Medicine, 98, 46-53. https://doi.org/10.1016/j.socscimed.2013.08.033

Rose-Ackerman, S. (1999). Corruption and government: causes, consequences, and reform. New York: Cambridge University Press.

Ross, S. A. (1973). The economic theory of agency: The principal's problem. The American Economic Review, 63(2), 134-139.

Rothstein, H.R., \& Hopewell, S. (2009). Grey Literature. In Cooper, H., Hedges, L. V., \& Valentine, J. C. (Eds.), The Handbook of Research Synthesis and Meta-Analysis (pp. 103-127). New York: Russell Sage Foundation

Savedoff, W. D., \& Hussmann, K. (2006). Why are health systems prone to corruption? Global Corruption Report 2006.

Sgueo, G. (2018). The Institutional Architecture of EU Anti-Fraud Measures: Overview of a Network (June), European Parliamentary Research Service. Retrieved from https://ssrn.com/abstract=3198118

Smith, R.D. (2004). Foreign direct investment and trade in health services: a review of the literature, Social Science and Medicine, 59(11), 2313-2323. https://doi.org/10.1016/j.socscimed.2004.03.021

Somogyvári, M. (2013). The Costs of Organisational Injustice in the Hungarian Health Care System, Journal of Business Ethics, 118(3), 543-560. https://doi.org/10.1007/s10551-012-1600-3

Stepurko, T., Pavlova, M., Gryga, I., Murauskiene, L., Groot, W. (2015). Informal payments for health care services: The case of Lithuania, Poland and Ukraine, Journal of Eurasian Studies, 6(1), 46-58. https://doi.org/10.1016/j.euras.2014.11.002

Thorpe, N., Deslich, S., Sikula, Sr., A., \& Coustasse, A. (2012). Combating Medicare Fraud: A Struggling Work In Progress, Franklin Business \& Law Journal, 4, 95-107.

Ugur, M., \& Dasgupta, N. (2011). Evidence on the economic growth impacts of corruption in low-income countries and beyond: a systematic review. London: EPPI-Centre, Social Science Research Unit, Institute of Education, University of London.

Vian, T. (2008). Review of corruption in the health sector: theory, methods and interventions. Health Policy \& 
Planning, 23(2). https://doi.org/10.1093/heapol/czm048

Vian, T., Brinkerhoff, D. W., Feeley, F. G., Salomon, M., \& Vien, N. T. K. (2012). Confronting Corruption in the Health Sector in Vietnam: Patterns and Prospects. Public Administration \& Development, 32(1), 49-63. https://doi.org/10.1002/pad.1607

WorldBank Development Committee. (2006). Strengthening World Bank Group Engagement on Governance and Anticorruption.

\section{Note}

Note 1. Please, note that not all publications included in our literature review have been cited.

\section{Copyrights}

Copyright for this article is retained by the author(s), with first publication rights granted to the journal.

This is an open-access article distributed under the terms and conditions of the Creative Commons Attribution license (http://creativecommons.org/licenses/by/4.0/). 